\title{
Hubungan Ekspansi Jaringan Kantor dan Kinerja Keuangan Terhadap Pertumbuhan Aset Bank Syariah
}

\author{
Dwi Nur'aini Ihsan \\ UIN Syarif Hidayatullah Jakarta \\ dwinuraini@uinjkt.ac.id
}

\begin{abstract}
This study tests Islamic banks in Indonesia for the period 2015 - May 2019 which aims to prove the influence of bank office network expansion and bank financial performance which is proxied by the ratio of CAR, BOPO, NOM and ROA to the growth of Islamic bank assets. The strategy of expanding the bank office network and achieving the performance of Islamic banks will have an impact on the growth of assets owned by the bank. This relationship analysis is basically to examine the extent of the relationship between bank expansion and bank ratios to the growth rate of assets. With a 5\% significance level, it is obtained that NOM and ROA do not have a significant effect on asset growth.
\end{abstract}

Keywords: bank expansion, financial performance, Islamic bank

\begin{abstract}
Abstrak
Penelitian ini melakukan pengujian terhadap bank syariah di Indonesia periode 2015 - Mei 2019 yang bertujuan untuk membuktikan pengaruh dari ekspansi jaringan kantor bank dan kinerja keuangan bank yang diproksikan dengan rasio CAR, BOPO, NOM dan ROA terhadap pertumbuhan aset bank syariah. Strategi ekspansi jaringan kantor bank dan pencapaian kinerja bank syariah akan berdampak pada pertumbuhan aset yang dimiliki oleh bank. Analisis hubungan ini pada dasarnya adalah untuk menguji sejauh mana hubungan ekspansi bank dan rasio-rasio bank terhadap tingkat pertumbuhan aset. Dengan tingkat signifikansi 5\% diperoleh bahwa NOM dan ROA tidak berpengaruh signifikan terhadap pertumbuhan aset.
\end{abstract}

Kata Kunci: ekspansi bank, kinerja keuangan, bank umum syariah 


\section{PENDAHULUAN}

Salah satu kebijakan pengembangan bank syariah di Indonesia adalah dengan dikeluarkannya Peraturan Bank Indonesia Nomor 14/26/PBI/2012 tentang kegiatan usaha dan jaringan kantor berdasarkan modal inti bank yang disertai dengan surat edaran Bank Indonesia No.15/8/DPbS tanggal 27 Maret 2013 perihal pembukaan jaringan kantor bank umum syariah dan unit usaha syariah berdasarkan modal inti. PBI tersebut mengatur mengenai pengelompokkan bank berdasarkan kegiatan usaha sesuai dengan besarnya modal inti, kewajiban bank untuk menyalurkan kredit atau pembiayaan produktif dan pembukaan jaringan kantor bank yang harus didukung dengan modal inti yang mencukupi. Bank yang akan membuka jaringan kantor haruslah bank yang memiliki modal inti yang masuk dalam kategori bank umum kelompok usaha BUKU 3 dan BUKU 4. Bank yang akan mengajukan rencana pembukaan jaringan kantor, wajib mencantumkan perhitungan ketersediaan alokasi modal inti dalam rencana bisnis bank (RBB) dengan menggunakan modal inti posisi akhir bulan September.

Pembukaan jaringan kantor bank syariah ditujukan dalam rangka untuk untuk memenuhi layanan perbankan berdasarkan prinsip syariah kepada masyarakat. Pembukaan jaringan kantor bank syariah bisa dalam bentuk kantor cabang atau dengan skema unit syariah. Diharapkan dengan bertambahnya jumlah kantor cabang bank akan semakin meningkat pertumbuhan aset dari bank syariah.

Data bulan September 2017 dan September 2018, bank umum syariah di Indonesia masuk dalam kategori bank umum kelompok usaha BUKU 1 dan BUKU 2 (lihat Tabel 1). Dan hanya Bank Syariah Mandiri yang masuk kategori BUKU 3. Dengan kategori BUKU 1 dan BUKU 2 tersebut maka kegiatan bank syariah akan dibatasi kegiatan usahanya, karena dinilai kurang efisien dalam menjalankan kegiatan usaha perbankan. Persyaratan modal minimum tersebut akan membuat bank syariah mengalami kesulitan melakukan ekspansi usahanya dengan membuka jaringan kantor cabangnya. Padahal, ekspansi kantor cabang bank akan memberikan kemudahan akses dan kedekatan layanan perbankan ke masyarakat dan hal ini akan menjadi salah satu faktor yang mempengaruhi pilihan nasabah dalam membuka rekening. Ekspansi juga akan meningkatkan pangsa pasar (market share) bank syariah secara nasional.

Strategi pembukaan jaringan kantor bank perlu didukung dengan kemampuan keuangan yang memadai, antara lain tercermin pada ketersediaan alokasi modal inti sesuai lokasi dan jenis kantor bank. Selain itu, dalam rangka perimbangan penyebaran jaringan kantor, bank didorong untuk melakukan perluasan ke wilayah yang kurang terlayani oleh jasa perbankan, guna mendukung upaya pengembangan pembangunan nasional. Layanan perbankan yang luas serta menjangkau semua lapisan masyarakat dengan ekspansi jaringan kantor tentunya akan berdampak kepada kinerja bank syariah. Kozo Harimaya dan Kazumine Kondo (2016) mendapatkan bahwa bank-bank regional yang memperluas jaringan cabang bank ke tingkat tertentu menunjukkan inefisiensi biaya yang lebih rendah. Ekspansi cabang bank berdampak menguntungkan bagi bank. 
Tabel 1. Modal Inti Bank Umum Syariah (Dalam Jutaan)

\begin{tabular}{lcccc}
\hline \multicolumn{1}{c}{ BANK } & \multicolumn{2}{c}{ Modal Inti } & \multicolumn{2}{c}{ Kategori Buku } \\
& September-2017 & September-2018 & September-2017 & September-2018 \\
\hline Bank Mega Syariah & 1.101 .329 & 1.117 .445 & BUKU 2 & BUKU 2 \\
Bank Muamalat Indonesia & 3.857 .070 & 3.822 .861 & BUKU 2 & BUKU 2 \\
Bank BNI Syariah & 2.693 .768 & 4.018 .075 & BUKU 2 & BUKU 2 \\
Bank Panin Dubai Syariah & 1.234 .514 & 1.578 .009 & BUKU 2 & BUKU 2 \\
Bank Syariah Mandiri & 6.453 .332 & 7.714 .923 & BUKU 3 & BUKU 3 \\
Bank BCA Syariah & 1.129 .046 & 1.168 .675 & BUKU 2 & BUKU 2 \\
Bank BRI Syariah & 2.526 .720 & 4.848 .200 & BUKU 2 & BUKU 2 \\
Bank Jabar Banten Syariah & 505.714 & 656.634 & BUKU 1 & BUKU 1 \\
Bank Aceh & 1.866 .154 & 1.724 .938 & BUKU 2 & BUKU 2 \\
Bank Syariah Bukopin & 883.747 & 779.946 & BUKU 1 & BUKU 1 \\
Bank Victoria Syariah & 228.658 & 262.389 & BUKU 1 & BUKU 1 \\
Bank Tabungan Pensiunan Nasional & 1.973 .808 & 3.586 .132 & BUKU 2 & BUKU 2 \\
Syariah & & & & BUKU 1 \\
Bank Maybank Syariah Indonesia & 547.387 & 547.387 & & BUKU 1 \\
\hline
\end{tabular}

Selain itu dengan adanya ekspansi jaringan kantor cabang akan semakin meningkatkan layanan perbankan ke semua lapisan masyarakat. Penelitian yang dilakukan oleh Mandiri Institute (2014) diketahui bahwa baru 20 persen masyarakat yang berusia diatas 15 tahun memiliki rekening bank di institusi keuangan formal dan 48 persen penduduk belum memiliki akses layanan keuangan (financial services) dari total penduduk sebanyak 249 juta jiwa di tahun 2013. Dari hasil penelitian tersebut berarti dari 100 orang usia diatas 15 tahun hanya 20 orang yang memiliki rekening dan dari 100 orang penduduk di Indonesia, 48 orang belum memiliki akses layanan keuangan.

Esti Sasanti dan Taufikur Rahman (2013) menyatakan bahwa perluasan jaringan kantor bank umum yang diukur dari jumlah deposito dan jumlah kredit tidak berpengaruh negatif terhadap tingkat profitabilitas BPR. Pertumbuhan ekonomi regional kabupaten/ kota yang diukur dari PDRB, Kinerja keuangan BPR yang diukur dari capital adequacy ratio (CAR), kualitas aktiva produktif (KAP), rasio biaya operasional terhadap pendapatan operasional (BOPO), loan to deposit ratio (LDR) dan current ratio (CR) tidak berpengaruh positif terhadap tingkat profitabilitas BPR.

Tabel 2. Jaringan Kantor Perbankan Syariah

\begin{tabular}{ccccccc}
\hline \multicolumn{1}{c}{ Indikator } & $\mathbf{2 0 1 4}$ & $\mathbf{2 0 1 5}$ & $\mathbf{2 0 1 6}$ & $\mathbf{2 0 1 7}$ & $\mathbf{2 0 1 8}$ & $\mathbf{2 0 1 9}$ \\
\hline Bank Umum Syariah & & & & & & \\
$1 \quad$ Jumlah Bank & 12 & 12 & 13 & 13 & 14 & 14 \\
$2 \quad$ Jumlah Kantor & 2.151 & 1.990 & 1.869 & 1.825 & 1.875 & 1.881 \\
\hline
\end{tabular}


Berdasarkan data dari statistik perbankan syariah Indonesia yang diterbitkan OJK diketahui jumlah jaringan kantor bank umum syariah dari tahun 2014 hingga Mei 2019 mengalami kenaikan yang cukup signifikan meskipun di 2017 mengalami penurunan jumlah kantor dari 1.869unit kantor di tahun 2016 menjadi 1.825 unit kantor di 2017 (Lihat Tabel 2). Prasetyo dan Sunaryo (2015) menyatakan bahwa penambahan jumlah cabang dan jumlah pegawai industri perbankan di Indonesia tidak berpengaruh signifikan terhadap perubahan rasio LDR, NPL, NIM, ROA dan ROE di tahun 2011-2012 (Lihat Tabel 3).

Tabel 3. Indikator Kinerja Bank Umum Syariah (2014 - 2018)

\begin{tabular}{lccccc}
\hline \multicolumn{1}{c}{ INDIKATOR UTAMA } & $\mathbf{2 0 1 4}$ & $\mathbf{2 0 1 5}$ & $\mathbf{2 0 1 6}$ & $\mathbf{2 0 1 7}$ & $\mathbf{2 0 1 8}$ \\
\hline Aset (Miliar Rp) & 204.961 & 213.423 & 254.184 & 288.027 & 316.691 \\
DPK (Miliar Rp) & 170.723 & 174.895 & 206.407 & 238.393 & 257.606 \\
Pembiayaan (Miliar Rp) & 147.944 & 153.968 & 177.482 & 189.789 & 202.298 \\
CAR & 15,74 & 15,02 & 16,63 & 17,91 & 20,39 \\
ROA & 0,41 & 0,49 & 0,63 & 0,63 & 1,28 \\
NPF & 4,95 & 4,84 & 4,42 & 4,76 & 3,26 \\
FDR & 86,66 & 88,03 & 85,99 & 79,61 & 78,53 \\
BOPO & 96,97 & 97,01 & 96,22 & 94,91 & 89,18 \\
\hline
\end{tabular}

Utami dan Hermanto (2013) menyatakan bahwa bank yang semakin terdiversifikasi akan memiliki interest margin dan tingkat bunga kredit yang lebih rendah relative terhadap bank yang kurang terdiversifikasi. Hubungan negatif ini berkaitan dengan strategi crossselling bank antara aktivitas kredit dengan aktivitas non-tradisional. Pendapatan komisi dan fee serta pendapatan trading memberikan penjelasan lebih jauh tentang efek diversifikasi produk terhadap nilai interest margin dan loan pricing bank.

Meskipun bank umum syariah masuk dalam kategori kelompok usaha BUKU 1 dan BUKU 2 serta rasio BOPO yang tinggi diatas 90\% (lihat Tabel 3) tetapi bank syariah tetap gencar menambah jaringan kantor atau cabangnya. Permodalan bank harus tunduk pada regulasi mengenai rasio kecukupan modal (CAR) sebesar 8\%. Selain itu penting bagi bank syariah untuk memiliki performance yang baik yang dapat diukur pada kinerja NOM dan ROA. Keputusan untuk ekspansi tentunya akan berpengaruh signifikan terhadap pertumbuhan total aset bank umum syariah di Indonesia. Oleh karena itu diperlukan analisa bagaimana pengaruh ekspansi jaringan kantor, CAR, BOPO, NOM dan ROA terhadap performance bank syariah di Indonesia.

\section{METODE}

Metode analisis yang digunakan dalam penelitian ini adalah metode kuantitatif. Analisis data kuantitatif adalah bentuk analisa yang menggunakan angka-angka dan perhitungan dengan metode statistik, maka data tersebut harus diklasifikasikan dalam kategori tertentu dengan menggunakan tabel-tabel tertentu. Model analisis penelitian ini menggunakan 
analisa regresi berganda. Jenis data yang digunakan adalah data sekunder yaitu data yang diperoleh dari informasi laporan keuangan yang terdapat di website OJK.

Penelitian ini menggunakan populasi data seluruh bank umum syariah di Indonesia pada periode tahun 2015 - Mei 2019. Data yang digunakan pada penelitian ini berasal dari laporan keuangan bulanan Bank Umum Syariah (BUS) dan data time series dari tahun 2015 hingga Mei 2019. Variable yang digunakan yaitu pertumbuhan aset sebagai variable dependen dan variable-variable independen terdiri atas jumlah cabang (X1), CAR (X2), BOPO (X3), ROA 9X4) dan NOM (X5). Hipotesis pada penelitian ini adalah jumlah cabang bank, CAR, BOPO, ROA dan NOM berpengaruh positif terhadap pertumbuhan aset bank syariah.

\section{HASIL DAN PEMBAHASAN}

Penelitian ini menggunakan model analisis regresi berganda untuk menganalisis pengaruh jumlah cabang bank, CAR, BOPO, ROA dan NOM terhadap pertumbuhan aset bank syariah dengan model dasar sebagai berikut:

Pertumbuhan Aset $=\alpha+\beta 1 \mathrm{JmlCab}+\beta 2 \mathrm{CAR}+\beta 3 \mathrm{BOPO}+\beta 4 \mathrm{ROA}+\beta 5 \mathrm{NOM}$

Dimana: JmlCab ialah jumlah cabang bank Syariah; CAR ialah Capital Adequacy Ratio; ROA ialah Return on Asset; NOM ialah Net Operating Margin; BOPO ialah Biaya Operasional pada Pendapatan Operasional.

Berdasarkan uji ANOVA atau F test pada Tabel 5, didapat angka signifikan (0.000) yang masih dibawah 0.05. Hal ini menunjukkan variable jumlah cabang bank, CAR, BOPO, ROA dan NOM mempengaruhi secara simultan pada pertumbuhan aset bank.

Pada uji statistik $t$ dilakukan untuk menguji hubungan secara parsial masing-masing variable independen berpengaruh terhadap variable dependen dengan kriteria nilai signifikan dibawah 0,05. Hasil analisis deskriptif data dapat dilihat pada Tabel 4 berikut ini:

Tabel 4. Deskriptif Data Descriptive Statistics

\begin{tabular}{lccccc}
\hline & N & Minimum & Maximum & Mean & Std. Deviation \\
\hline ASET & 53 & 197385.00 & 318058.00 & 254188.8679 & 42572.78428 \\
JMLH CABAN & 53 & 1681.00 & 2157.00 & 1905.4151 & 114.02352 \\
CAR & 53 & 14.09 & 21.39 & 16.9283 & 2.27099 \\
BOPO & 53 & 86.29 & 99.04 & 93.2645 & 3.46281 \\
ROA & 53 & .16 & 1.56 & .9060 & .35660 \\
NOM & 53 & .17 & 1.76 & 1.0149 & .41475 \\
Valid N (listwise) & 53 & & & & \\
\hline
\end{tabular}

Tabel 5 menghasilkan pengujian secara parsial diketahui bahwa pengaruh jumlah cabang bank (X1) dan rasio BOPO (X3) menunjukkan hubungan yang negatif terhadap pertumbuhan aset bank dan signifikan. Pada rasio CAR (X2) memiliki hubungan positif 
dan signifikan. Rasio NOM (X5) memiliki hubungan negatif dan tidak signifikan pada pertumbuhan aset. Sedangkan ROA (X4) memiliki hubungan positif tetapi tidak signifikan.

Tabel 5. Hasil Uji F (anova ${ }^{a}$ )

\begin{tabular}{llccccc}
\hline & Model & Sum of Squares & Df & Mean Square & F & Sig. \\
\hline \multirow{2}{*}{1} & Regression & 87570613863.809 & 5 & 17514122772.762 & 123.295 & $.000^{\mathrm{b}}$ \\
& Residual & 6676368106.266 & 47 & 142050385.240 & & \\
& Total & 94246981970.076 & 52 & & & \\
\hline
\end{tabular}

a. Dependent Variable: asset, b. Predictors: (Constant), nom, jmlcab, car, bopo, roa

Koefisien regresi untuk variable JMLCAB sebesar -87.815 dan nilai signifikansi 0.000; variable CAR 9762.833 dan nilai signifikansi 0.000; BOPO sebesar -9573.603 dan nilai signifikansi 0.000; ROA sebesar 135675.109 dan nilai signifikansi 0.141; dan NOM nilai koefisiennya-167372.121 dengan tingkat signifikansinya sebesar 0.026. Sehingga secara parsial yang tidak signifikan terhadap pertumbuhan aset adalah rasio ROA dan Rasio NOM.

Tabel 6. Hasil Uji t (Coefficients ${ }^{a}$ )

\begin{tabular}{|c|c|c|c|c|c|c|c|c|}
\hline & \multirow[t]{2}{*}{ Model } & \multicolumn{2}{|c|}{$\begin{array}{c}\text { Unstandardized } \\
\text { Coefficients }\end{array}$} & \multirow{2}{*}{$\begin{array}{c}\text { Standardized } \\
\text { Coefficients } \\
\text { Beta }\end{array}$} & \multirow[t]{2}{*}{$\mathbf{t}$} & \multirow[t]{2}{*}{ Sig. } & \multicolumn{2}{|c|}{$\begin{array}{l}\text { Collinearity } \\
\text { Statistics }\end{array}$} \\
\hline & & B & Std. Error & & & & Tolerance & VIF \\
\hline \multirow{6}{*}{1} & (Constan) & 1196062.344 & 271789.315 & & 4.401 & .000 & & \\
\hline & Jmlcab & -87.815 & 16.945 & -.235 & -5.182 & .000 & .732 & 1.367 \\
\hline & Car & 9762.833 & 1654.524 & .521 & 5.901 & .000 & .193 & 5.168 \\
\hline & Bopo & -9573.603 & 2487.900 & -.779 & -3.848 & .000 & .037 & 27.170 \\
\hline & Roa & 135675.109 & 90524.104 & 1.136 & 1.499 & .141 & .003 & 381.461 \\
\hline & Nom & -167372.121 & 72583.780 & -1.631 & -2.306 & .026 & .003 & 331.752 \\
\hline
\end{tabular}

a. Dependent Variable: asset

Sehingga hipotesis bahwa ROA dan NOM mempengaruhi pertumbuhan aset ditolak dan jumlah cabang, CAR dan BOPO mempengaruhi secara signifikan terhadap pertumbuhan aset bank syariah. Persamaan regresi dari Tabel 5 diperoleh sebagai berikut:

Pertumbuhan aset: 1196062.3 - 87.8JmlCab + 9762.8CAR - 9573.6BOPO +135675.1ROA167372.1NOM

Tabel 7. Hasil Koefisien Determinasi (Total Aset) Model Summary

\begin{tabular}{cccccc}
\hline Model & R & R Square & $\begin{array}{c}\text { Adjusted R } \\
\text { Square }\end{array}$ & $\begin{array}{c}\text { Std. Error of the } \\
\text { Estimate }\end{array}$ & Durbin-Watson \\
\hline 1 & $.964^{\mathrm{a}}$ & .929 & .922 & 11918.48922 & .653 \\
\hline
\end{tabular}

(a) Predictors: (Constant), nom, jmlcab, car, bopo, roa, (b) Dependent Variable: asset 
Berdasarkan data Tabel 7, strategi ekspansi dan kinerja keuangan memberikan pengaruh yang sangat besar terhadap total aset bank dengan Adjusted $R$ Square sebesar 92\%. Tabel 7 menjelaskan bahwa strategi ekspansi yang dilakukan oleh bank syariah dan kinerja keuangan memberikan pengaruh sebesar 92\% terhadap pertumbuhan aset bank.

Jumlah jaringan kantor bank memiliki pengaruh signifikan terhadap pertumbuhan aset, karena dengan semakin luasnya jaringan kantor bank akan meningkatkan penghimpunan dana yang berasal dari masyarakat dan bank dapat menggunakannya untuk peningkatan aset bank. Hal ini sejalan dengan penelitian yang dilakukan oleh Syafrida dan Ahmad (2011) bahwa variabel internal yang mempengaruhi pertumbuhan aset perbankan syariah secara signifikan hanya jumlah kantor, FDR dan biaya promosi.

Penelitian ini menemukan bahwa rasio ROA dan NOM tidak signifikan mempengaruhi pertumbuhan aset bank. Hal ini mengindikasikan bahwa pertumbuhan aset bank tidak dipengaruhi dari profitabilitas dan pendapatan operasional setelah bagi hasil dan beban opersaional dengan rata-rata aktiva produktif bank. Hal ini sejalan dengan Prasetyo dan Sunaryo (2015) bahwa dengan penambahan jumlah cabang dan jumlah pegawai terhadap rasio-rasio BOPO, Sunaryo LDR, NPL, NIM, ROA dan ROE tidak berpengaruh signifikan dan membuktikan bahwa keefisienan bank syariah bukan pada penambahan jaringan kantor bank tetapi pada hal biaya dana. Syafrida dan Ahmad (2011) menjelaskan terdapat beberapa faktor yang mempengaruhi pertumbuhan aset bank syariah di Indonesia, yaitu office chanelling, jumlah uang beredar (M2), jumlah kantor, NPF, biaya promosi, pendidikan dan pelatihan, jumlah DPK, serta rasio FDR.

Prasetyo dan Sunaryo (2015) menyatakan kebijakan sebagian besar industri perbankan untuk membuka cabang baru guna melayani nasabah lebih baik lagi dan menambah jangkauan pelayanan ke seluruh wilayah Indonesia masih tepat. Begitu pula penambahan jumlah jaringan kantor berdampak kecil terhadap terhadap performance bank yang diproksikan dengan rasio ROA hal ini ditunjukkan pada nilai Adjusted $R$ Square sebesar 12\%. Strategi ekspansi bank syariah di Indonesia pada kurun waktu 2007 - 2018 melalui penambahan jumlah jaringan kantor bank tidak memberikan kontribusi pada peningkatan profitabilitas bank.

NOM sebagai rasio yang digunakan untuk mengukur kemampuan manajemen dalam mengelola aktiva produktifnya untuk mendapatkan pendapatan bagi hasil. Dari rasio ini sebenarnya dapat dilihat bagaimana kemampuan bank dalam memaksimalkan pengelolaan terhadap aktiva produktifnya sehingga akan mempengaruhi pertumbuhan aset bank. Apalagi dengan modal inti bank syariah yang secara umum berada pada status BUKU 1 dan BUKU 2 dimana bank harus hati-hati dan efektif dalam pengelolaan aktiva untuk pertumbuhan asetnya. Tidak berpengaruhnya rasio ROA dan NOM ini dikarenakan rasio BOPO bank umum syariah sangat tinggi diatas 90\% sehingga mempengaruhi size (ukuran) perusahaan.

Rasio CAR merupakan salah satu indikator modal bank yang sangat penting. Modal Bank harus dapat digunakan untuk memelihara bank dari resiko kerugian serta untuk memenuhi persyaratan modal minimum. Muhammad (2002) menyatakan bahwa modal juga penting bagi bank untuk mendukung rencana ekspansi jaringan kantor bank. Abusharba, 
dkk (2013) menyatakan faktor penentu rasio kecukupan modal pada industri perbankan syariah Indonesia berhubungan positif dengan ROA, NPF, DEP, FDR san OEOI. Berbeda dengan Al Ichsan, dkk (2014) menyatakan bahwa CAR memiliki hubungan negatif terhadap pertumbuhan aset bank.

BOPO dijadikan variabel independen yang mempengaruhi pertumbuhan aset bank dan sebagai salah satu rasio efisiensi yang digunakan untuk mengukur bagaimana kemampuan manajemen bank dalam mengendalikan biaya operasional terhadap pendapatan operasional. Jika BOPO dapat ditekan oleh bank syariah maka semakin efisien bank dalam menjalankan aktivitas kegiatan usahanya. Bank syariah perlu melakukan strategi kebijakan inklusif keuangan guna menurunkan biaya operasionalnya salah satunya adalah melalui melalui branchless banking dan layanan digital, dimana layanan jasa keuangan perbankan bisa dilakukan di luar cabang bank dengan menggunakan teknologi informasi. Beberapa penelitian tentang branchless banking seperti Al-Astal (2008), Ahmad dan Sreenivas (2013) menyatakan bahwa branchless banking dapat mengurangi biaya infrastruktur untuk kantor cabang, sehingga terbukti efisien.

\section{SIMPULAN}

Penelitian ini bertujuan untuk menguji dampak strategi ekspansi jaringan kantor cabang bank, rasio-rasio keuangan yang digunakan untuk mengukur bagaimana dampaknya terhadap pertumbuhan aset bank. Penambahan jaringan kantor bank dan rasio CAR, BOPO berpengaruh pada pertumbuhan aset bank, namun pada rasio ROA dan NOM tidak berpengaruh signifikan di tahun 2015 - Mei 2019. Penelitian ini memberikan rekomendasi agar bank syariah tetap menjaga kecukupan modalnya, menekan BOPO agar lebih efisien dan melakukan ekspansi dengan pertimbangan yang baik agar efisiensi pada biaya operasional terhadap pendapatan operasional terjaga dengan baik.

\section{PUSTAKA ACUAN}

Abusharba, Mohammed T. dkk. (2013). Determinants of Capital Adequacy Ratio (CAR) in Indonesian Islamic Commercial Banks. Global Review of Accounting and Finance. 4 (1): 159-170.

Al Arif, M. N. R. (2011). The Effects of Macroeconomic Variables on Profit-Sharing Yield Pricing. Economic Journal of Emerging Markets. 3(3): 235-244.

Al Arif, M. N. R., \& Hanifah, H. (2017). Determinan Deposito Pada Bank Umum Syariah: Model Regresi Panel. Jurnal Ekonomi Kuantitatif Terapan. 10(1): 39-46. doi: https:// doi. org/10.24843/JEKT.2017. v10.i01.p05.

Al Ichsan., A., Muhammad., \& Rahmatia. (2014). Hubungan Kinerja keuangan, Profitabilitas dan Pertumbuhan Aset Bank Pembangunan Daerah (BPD) Di Indonesia. Jurnal Analisis. 3 (2): $195-200$.

Andhika, Y. D. (2017). Faktor-faktor Yang Mempengaruhi Capital Adequacy Ratio (CAR) Bank Umum Syariah di Indonesia. Jurnal Ekonomi Syariah Teori dan Terapan. 4(4): 312-323. 
Arafat, W. Manajemen Perbankan Indonesia Teori dan Implementasi. Pustaka LP3ES Indonesia. Jakarta.

Dimitris, I, G. (2008). Cost efficiency impact of bank branch characteristics and location: An illustrative application to Greek bank branches. Managerial Finance. 34(3): $172-185$.

Drake, L., \& Howcroft, B. (2002). An insight into the size efficiency of a UK bank branch network. Managerial Finance. 28(9): 24 - 36.

Gerald P. Dwyer, Jr., (1997). Branching Restrictions and Banking Offices. Managerial Finance. 23(2): $65-77$.

Harimaya, Kozo \& Kondo, Kazumine (2016). Effects Of Branch Expansion On Bank Efficiency: Evidence From Japanese Regional Banks. Managerial Finance. 42(2): 82 - 94.

Ihsan, D, N. (2013). Analisa Laporan Keuangan Bank Syariah. Jakarta: Lemlit UIN Syarif Hidayatullah Jakarta.

Ismal, R. (2011). The Indonesian Islamic Banking; Theory and Practices. Jakarta: Gramata.

Laderman, E. (2000). The Potential Diversification and Failure Reduction Benefits of Bank Expansion into NonBanking Activities. Working Paper Series 2000-2001. Federal Reserve Bank of San Francisco.

Mandiri Institute. (2014). Research Paper Series on Financial Inclusion Current State of Financial Inclusion in Indonesia, Agustus 2014 diakses melalui: http://mandiri-institute. id/files/research-paper-series-on-financial-inclusion-current-state-of financial-inclusionin-indonesia/?upf=vw\&id=1246 diakses tanggal 1 Februari 2016.

Muhammad. (2002). Manajemen Bank Syariah. Yogyakarta: UPP AMP YKPN.

Nuviyanti \& Anggono, A. (2014). Determinants of Capital Adequacy Ratio (CAR) in 19 Commercial Banks (Case Study: Period 2008-2013). Journal of Business and Management. 3(7): 752-764.

Peraturan Bank Indonesia Nomor 9/1/PBI/2007 tentang Sistem Penilaian Tingkat Kesehatan Bank Umum Berdasarkan Prinsip Syariah.

Peraturan Bank Indonesia Nomor 14/26/PBI/2012 tanggal 27 Desember 2012 tentang Kegiatan Usaha Dan Jaringan Kantor Berdasarkan Modal Inti Bank.

Peraturan 0JK Nomor 8/POJK.03/2014 tentang penilaian tingkat kesehatan bank umum syariah dan unit usaha syariah dengan pendekatan berdasarkan risiko (Risk-based Bank Rating).

Prasetyo, H., \& Sunaryo, S. (2015). Pengaruh Ekspansi Jumlah Cabang Dan Jumlah Pegawai Terhadap Kinerja Industri Perbankan Di Indonesia. Buletin Ekonomi Moneter dan Perbankan. 18(1): 85- 106.

Riduwan \& Kuncoro, E A. (2011). Cara Mudah Menggunakan dan Memaknai Path Analysis (Analisis Jalur). Bandung: Alfabeta.

Rivai, Veithzal dkk. (2013). Commercial Bank Management: Manajemen Perbankan dari Teori ke Praktik. Jakarta: Rajawali Pers. 
Sasanti, E., \& Rahman, Taufikur (2013). Pengaruh Perluasan Jaringan Kantor Bank Umum, Pertumbuhan Ekonomi Regional Dan Kinerja Keuangan BPR Terhadap Tingkat Profitabilitas BPR Di Wilayah Pengawasan Kantor Bank Indonesia Surabaya. Jurnal Accounting and Business Information Systems (ABIS). 4.

Sarah, H. (2015). Dampak Branchless Banking Terhadap Kinerja Keuangan PT Bank Muamalat Indonesia Tbk. Jurnal Al-Muzara'ah. 3 (2): 135-157.

Sugiyono. (2003). Metode Penelitian Bisnis. Bandung: Alfabeta.

Sunyoto, D. (2009). Analisis Regresi dan Uji Hipotesis. Yogyakarta: Media Pressindo.

Surat Edaran Bank Indonesia No.15/8/DPbS tanggal 27 Maret 2013 perihal Pembukaan Jaringan Kantor Bank Umum Syariah Dan Unit Usaha Syariah Berdasarkan Modal Inti.

Syafrida, I., \& Abror, Ahmad (2011). Faktor-faktor Internal dan Eksternal Yang Mempengaruhi Pertumbuhan Aset Perbankan Syariah di Indonesia. Jurnal Ekonomi dan Bisnis. 10(1): 19-24.

Tanjung, H., \& Devi, A. (2013). Metodologi Penelitian Ekonomi Islam. Jakarta: Gramata.

Tristiningtyas, V., \& Mutaher, Osmad (2013). Analisis Faktor-faktor Yang Mempengaruhi Kinerja Keuangan pada Bank Umum Syariah di Indonesia. Jurnal Akuntansi Indonesia. 3 (2): 131-145.

Tsolas, I, E., \& Giokas, Dimitris I (2012). Bank branch efficiency evaluation by means of least absolute deviations and DEA. Managerial Finance. 38(8): 768 - 785.

Utami, Desi Sri Wahyu \& Hermanto, Bambang. Ekspansi Layanan Jasa Perbankan Pada Bank Umum Konvensional Di Indonesia: Implikasi Terhadap Interest Margin Dan Loan Pricing.

Zhang, Tina Xiaotian \& Wang, Yong (2014). Production efficiency of Chinese banks: a revisit. Managerial Finance. 40(10): 969 - 986. 